\title{
The incidence of adverse reactions to drugs
}

\author{
O. L. WADE \\ From the Department of Clinical Pharmacology, University of Birmingham
}

Concern about adverse reactions to drugs is not new. In 1887 at a meeting in Manchester the British Medical Association set up a small committee to examine the sudden and unexpected deaths which sometimes occurred during chloroform anaesthesia. This was the first collaborative investigation of an adverse reaction of a drug in human subjects. Professor McKendrick, Professor of Physiology in Glasgow, and Dr Coats, pathologist, and $\mathrm{Dr}$ Newman, pathological chemist, at the Western Infirmary, Glasgow (1880) reported that chloroform was hazardous in man not only because excessive doses depressed respiration but because small doses had a deleterious effect on the heart and might cause cardiac arrest. This report was contrary to the experience of many who had used chloroform extensively. Its findings were repudiated by Surgeon Major Lawrie, Residency Surgeon at Hyderabad in the Deccan, with such heat that it is surprising that the now yellowing pages of the Lancet of 1889 and 1890 are not a little charred. Major Lawrie appointed two Hyderabad Chloroform Commissions, on both of which he sat as President. Following the extensive administration of chloroform to dogs that Commission in its final report stated, in the words of a contemporary Anglo-Indian, that chloroform given in doses which did not cause respiratory depression was 'as safe as whisky and water' (Lawrie, Brunton, Bomford, and Hakin, 1890). But the report received little attention in Britain for here it was already indisputable that in human beings sudden death did sometimes occur in the early stages of chloroform anaesthesia.

This ancient controversy is worth recalling. It not only showed for the first time the enormous emotion that may be aroused in doctors when a drug which they value is found to cause serious adverse reactions, but it also demonstrated, although the lesson has yet to be fully appreciated, that the administration of a drug to animals may fail to reveal its hazards in man.

Towards the end of the first World War another collaborative investigation concerning an adverse reaction to a drug was instituted. The Medical Research Committee, later to become the present
Medical Research Council, appointed a 'Special Committee on the Manufacture, Biological Testing and Clinical Administration of Salvarsan and its Substitutes'. Its enquiries followed an outbreak of acute yellow atrophy due to neoarsphenamine benzoate at Cherry Hinton Hospital near Cambridge in 1917 and 1918. The Committee reported (Medical Research Council, 1922) that the most probable cause of the outbreak was the toxicity of organoarsenical compounds. But Professor Stuart McDonald, Professor of Pathology at Newcastle, suspected that there was an additional factor causing the epidemic of jaundice which was probably microbial infection (McDonald, 1918). The aetiology of this jaundice was in retrospect probably serum hepatitis. By a strange coincidence the Committee also made a report of a peculiar outbreak of malaria among patients treated with neoarsphenamine ' 606 ' at Portobello Hospital, Dublin. Eight soldiers had died, and Professor A. C. O'Sullivan, Professor of Pathology at Trinity, found their organs full of malaria parasites, although only one of them was known to have served in a tropical country. The Committee found no reason to dissent from Professor O'Sullivan's opinion that the infection had been conveyed from one or more carriers of the disease to others through the apparatus for injecting ' 606 ', the blood of the carrier regurgitating into the last segment of the rubber tubing remaining in the crevices there and being washed into the veins of the next patient. If the hazard of crossinfection had been considered as a cause of the epidemic of jaundice at Cherry Hinton Hospital identification of an infectious cause of jaundice might have been made 20 years earlier than was the case.

The introduction of the sulphonamides in the late 1930s brought familiarity with adverse reactions to all physicians. But these drugs, and later penicillin, streptomycin, and the adrenocorticosteroids, led to such advances in medical treatment that adverse reactions, although recognized, caused no great anxiety. This complacency was shattered in 1961. At a congress of gynaecologists at Kiel on 19-20 October 1961, von Massenbach from Lubeck, Lenz from Hamburg, and Wiedemann from Kiel drew 
attention to the large number of children who had recently been born in Germany with hypoplastic or aplasticlimb deformities. A month later, at a paediatrics meeting in Dusseldorf, Lenz first suggested that the hypnotic drug thalidomide might be the responsible agent (Taussig, 1962). Thalidomide was marketed in Germany under a number of proprietary names and often was compounded with analgesics for the treatment of pain, cough, and insomnia. Not only were these preparations widely prescribed by doctors but they were purchased over the counter by the public. The profusion of preparations and names made retrospective inquiries about the medicines women had used in pregnancy difficult but Lenz's suspicions were soon confirmed. It is now believed that more than 6000 deformed babies were born in West Germany and some 500 in Britain as a result of the use of thalidomide. Many of these children still live, and remain a grim reminder of a tragedy that shocked the world.

One result of the public outcry after the thalidomide tragedy was that governments in many countries established organizations to ensure that adequate and appropriate toxicity tests were carried out before new drugs were used in human beings. However, as it became recognized that the results of tests in animals cannot be directly extrapolated to man, an urgent need developed for monitoring the use of drugs, especially newly introduced drugs, to identify adverse reactions as soon as possible. In Britain a report on the assessment of drug toxicity which was prepared for the Medical Research Council (1963) not only gave advice about the way in which a system of notification of adverse reactions by doctors using drugs should be established but stated: 'Early recognition alone is not always enough. The purpose of determining the toxic effects (of a drug) in man will usually be to obtain intelligent restriction of its further use. To make such a decision possible it is necessary not only to recognize the toxic effect but also to estimate its incidence and to compare that with the danger of the diseases for which the drug is being used.'

These wise words bear repetition for hasty and unnecessary decisions to ban the use of a drug have been a feature of recent years and are often the result of undue, unbalanced, and sometimes premature publicity by the press which lead to overreaction of the public or politicians. It is, however, now widely recognized that there is a need not only to identify the adverse reactions to a drug but to determine their incidence in relation to the use of the drug. The data available to answer such questions have come from sources each of which has had its limitations.

\section{Medical Literature}

Although there was increasing awareness of the् serious nature of adverse reactions to certain drugg following the introduction of the sulphonamides $\mathrm{i}$ 产 1935, it was considered sufficient throughout the 1950 s to leave the duty of reporting the toxic effects of drugs to individual physicians or pharmacolos gists who usually reported them in articles or letters in medical journals. It is, however, usually difficulP for a physician to establish the relationship between an unexpected toxic effect and a drug. The patien may be receiving many drugs and a single physiciais may seldom see the same adverse reaction to a drug more than once or twice in his professional life Nevertheless since 1957 Dr L. Meyler and his. colleagues have published a number of most valuable surveys of reports of adverse reactions t $\Theta$ drugs occurring in the world literature (Meyler1957; Meyler and Herxheimer, 1968). These survey£ are of great value as works of reference, for the reader can rapidly ascertain what reactions have been reported with any given drug. However, they, seldom provide reliable information about the incidence of reactions and indeed may give a false impression of the incidence, for many reports ma\& appear about certain reactions of special interest to physicians or pharmacologists.

\section{The Registries Reports of Adverse Reactions}

In 1951 two American haematologists, Wintrobe an Sturgeon, found by accident that each had seen two or three cases of aplastic anaemia in patients़ who had been treated with chloramphenicol. It was Dr Wintrobe's idea to establish a Registry of Blood Dyscrasias and between 1955 and 1962 reports of 1195 patients with blood dyscrasias suspected aş due to drugs were received. The number of report received was small: this was due to poor publicity? the novelty of the scheme, and the dauntingly detailec form which had to be filled in. There was also anxiety? which persists in the United States, that by reporting an illness as due to a drug he has prescribed, of physician might expose himself to a charge of negligence by his patient. The establishment of this registry by $\mathrm{Dr}$ Wintrobe marks the beginning of systemic monitoring of adverse reactions to druge (Erslev and Wintrobe, 1962).

After the thalidomide catastrophe registries of adverse reactions were established in a number of countries. Their main purpose is to provide an earlyo warning that a drug causes an adverse reaction. If is clear, however, that only a small proportion of adverse reactions that occur are reported. In the United Kingdom in 1966 when the relationship 
between the oral contraceptive pill and thrombosis was of wide public interest, it was found that in a sample of 53 women who had died of thrombotic illnesses and who were known by their family doctor to be on oral contraceptives only eight had been reported to the Committee on Safety of Drugs (Inman and Vessey, 1968). It is known, too, that many deaths of asthmatic patients using isoprenaline aerosols were never reported, but this was because the relationship between these aerosols and sudden death was unsuspected (Inman and Adelstein, 1969).

Yet despite serious defects these registries still constitute one of our most valuable sources of information about adverse reactions. The Committee on Safety of Medicines (the name was changed when the Medicines Act was passed in 1968) receives about 350 reports a month. It is now possible to characterize a profile of the reactions of a given drug or group of drugs. When a new but related drug is marketed suspicions may be aroused if reports of an unexpected reaction such as jaundice begin to arrive (Wade, 1970).

The Committee's policy has always been to ask for a simple report from doctors and a supply of prepaid yellow postcards is sent to every medical practitioner. They are asked to report all unexpected and all serious adverse reactions to drugs, especially those suspected to be due to new drugs. It has been a disappointment that so few reports of adverse reactions to drugs have come to the Committee from hospitals. Reporting from a hospital can be greatly increased if a physician on the staff takes a major interest in the problem and if junior doctors, nurses, or pharmacists can be employed as 'drug safety officers'. In the West Midlands Region a Midlands Adverse Reactions Study Group has been formed and reporting from a number of the hospitals has increased greatly. It may be possible to stimulate the interest of family doctors working in the community, and this is desirable because the use of drugs by them is very different from the use in hospitals.

\section{Intensive Monitoring}

The seriousness of an adverse reaction depends not only on its nature but also on its frequency in relation to the use of a drug. In the US Army Custer (1946) determined the incidence of aplastic anaemia due to the antimalarial drug mepacrine with a precision which will seldom be equalled. He showed that the incidence was 2.84 per 100000 men taking mepacrine compared with 0.1 per 100000 men not taking mepacrine. In spite of this low incidence, Custer's evidence that mepacrine can cause aplastic anaemia is accepted because he surveyed millions of troops with excellent medical records.

Intensive monitoring has been developed in hospitals. Patients are kept under surveillance, all drugs administered are recorded, and any event which might be an adverse reaction to a drug is noted. In a survey carried out at the Belfast City Hospital, Hurwitz and Wade (1969) showed that about $10 \%$ of patients in our wards had adverse reactions to drugs (table $I$ ), that these tended to be commoner in women than men (table II), and were more frequent in the aged than in the young (table III). It was interesting to find that patients who on admission had a history of previous drug reactions or of allergic illness were at greater risk than those who had no such history (table IV) and it was possible to identify certain drugs (table V) which caused a high incidence of reactions and certain combinations of drugs (table VI). Similar findings have been reported by others.

\begin{tabular}{lllr}
\hline & No. & $\begin{array}{l}\text { Adverse Reaction } \\
\text { to Drugs }\end{array}$ & Rate (\%) \\
\hline Patients admitted & 1268 & 118 & $9 \cdot 3$ \\
No. given drugs & 1160 & 118 & $10 \cdot 2$ \\
\hline
\end{tabular}

Table I Adverse reactions to drugs in hospitals

\begin{tabular}{lccc}
\hline Sex & \multicolumn{2}{l}{ No. of Patients } & \multirow{2}{*}{ Rate (\%) } \\
\cline { 2 - 3 } & $\begin{array}{lll}\text { Given } \\
\text { Drugs }\end{array}$ & $\begin{array}{l}\text { With } \\
\text { Reactions }\end{array}$ & \\
\hline Males & 682 & 50 & $7 \cdot 3$ \\
Females & 478 & 68 & $14 \cdot 2$ \\
Total & 1160 & 118 & $10 \cdot 2$ \\
\hline
\end{tabular}

Table II Sex and drug reaction $0.01>\mathrm{P}>0.001$

\begin{tabular}{lccc}
\hline $\begin{array}{l}\text { Age of } \\
\text { Patients } \\
\text { (years) }\end{array}$ & $\begin{array}{l}\text { No. Given } \\
\text { Drugs }\end{array}$ & $\begin{array}{l}\text { No. with } \\
\text { Reactions }\end{array}$ & Rate (\%) \\
\hline $10-19$ & 64 & 2 & $3 \cdot 1$ \\
$20-29$ & 100 & 3 & $3 \cdot 0$ \\
$30-39$ & 122 & 7 & $5 \cdot 7$ \\
$40-49$ & 159 & 12 & $7 \cdot 5$ \\
$50-59$ & 222 & 18 & $8 \cdot 1$ \\
$60-69$ & 252 & 27 & $10 \cdot 7$ \\
$70-79$ & 178 & 38 & $21 \cdot 3$ \\
$80-89$ & 59 & 11 & $18 \cdot 6$ \\
$90-99$ & 4 & 0 & 0 \\
Total & 1160 & 118 & $10 \cdot 2$ \\
\hline
\end{tabular}

Table III Age and drug reactions

Rank correlation coefficient $=+0.86$ 


\begin{tabular}{|c|c|c|c|}
\hline & Previous Reactions & Allergic Disease & Jaundice \\
\hline $\begin{array}{l}1042 \text { patients with no drug reactions } \\
118 \text { patients with drug reactions } \\
P\end{array}$ & $\begin{array}{l}70(6 \cdot 7 \%) \\
27(22 \cdot 9 \%) \\
<0.001\end{array}$ & $\begin{array}{l}48(4 \cdot 6 \%) \\
19(16 \cdot 1 \%) \\
<0.001 \%\end{array}$ & $\begin{array}{l}46(4.4 \%) \\
4(3.4 \%) \\
0.70>P>0.50\end{array}$ \\
\hline
\end{tabular}

Table IV Adverse reactions and a history of previous reactions, allergic disease, and jaundice

\begin{tabular}{llll}
\hline Drug & \multicolumn{2}{c}{ No. of Patients } & Rate (\%) \\
\cline { 2 - 3 } & Given Drugs & With Reactions & \\
\hline Ampicillin & 103 & 8 & $7 \cdot 8$ \\
Other penicillins & 167 & 0 & 0 \\
Orciprenaline & 74 & 6 & $8 \cdot 1$ \\
Choline theophyllinate & 100 & 5 & $5 \cdot 0$ \\
Methoxyphenamine & 133 & 1 & $0 \cdot 8$ \\
Morphine & 90 & 5 & $5 \cdot 6$ \\
Methadone & 78 & 2 & $2 \cdot 6$ \\
Opium & 57 & 1 & $1 \cdot 8$ \\
Pethidine & 200 & 1 & $0 \cdot 5$ \\
Dihydrocodeine & 76 & 0 & 0 \\
Paracetamol & 128 & 0 & 0 \\
\hline
\end{tabular}

Table V Drugs and adverse reactions

\begin{tabular}{lccc}
\hline & $\begin{array}{l}\text { Patients } \\
\text { Given } \\
\text { Drugs }\end{array}$ & $\begin{array}{l}\text { Reactions } \\
\text { to } \\
\text { Digitalis }\end{array}$ & $\begin{array}{l}\text { Reaction } \\
\text { Rate } \\
(\%)\end{array}$ \\
\hline $\begin{array}{l}\text { Digitalis alone } \\
\text { Digitalis and frusemide }\end{array}$ & 53 & 5 & 9 \\
$\begin{array}{l}\text { Digitalis and hydroflumethazide } \\
\text { Digitalis, frusemide and }\end{array}$ & 23 & 16 & 20 \\
$\begin{array}{l}\text { hydroflumethazide } \\
\text { Digitalis and other diuretics }\end{array}$ & 18 & 6 & 35 \\
Digitalis and all diuretics & 24 & 4 & 33 \\
\hline
\end{tabular}

Table VI Reactions to digitalis and diuretics

\section{The Therapeutic Audit}

The thoughtful doctor will realize that it is now enough to establish and improve the monitoring of adverse reactions to drugs. If sensible decisions are्e to be made much needs to be known about the use of the drug. How widely is it used? Whø prescribes it? Which patients receive it? For what illnesses? What good does it do? What other drug? are available?

Studies on the use of drugs in the community are very much in their infancy. Dr Helen Hood and $\mathrm{E}$ had the fortunate opportunity to have access to details of all prescriptions written by family doctors in Northern Ireland from 1966 onwards (Wadec 1970). All the data are recorded on computer taper to allow payments to be made to pharmacists and we have been able to follow the change of prescribing of individual drugs over time. Figure 1 shows the changes in the prescribing of hypnotic drugs between 1966 and 1970 (Wade and Hood, 1972a). The grea\& increase in the prescribing of Mandrax was probably related to intense and skilful advertising of this preparation; its use decreased after 1969 and nitrazepam (Mogodon) is now the group leader. Of special interest, in view of the deaths caused by
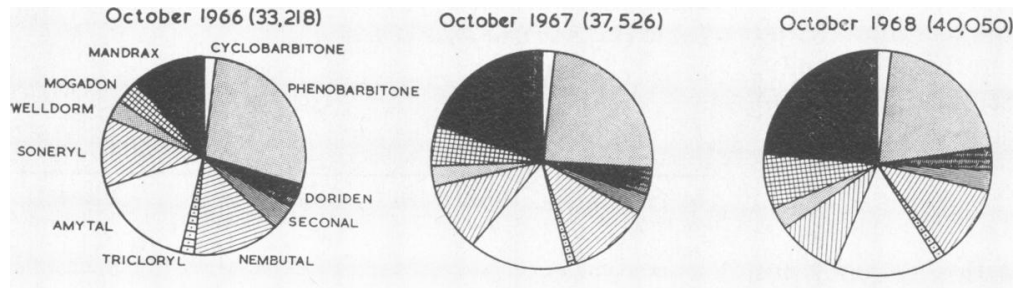

Fig 1 The prescribing of hypnotic drugs in Northern Ireland 1966-1970.

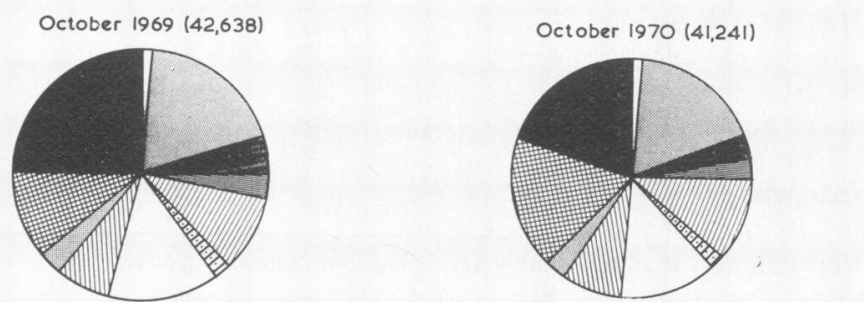




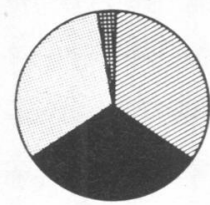

October 1971 (8177 prescriptions)

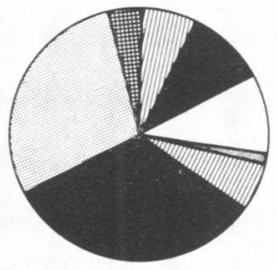

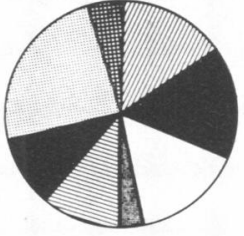

Fig 2 The prescribing of bronchodilator aerosols in Northern Ireland 1967-1973. excessive use of isoprenaline aerosols, is a study of the use of bronchodilator aerosols. This shows (fig 2) a considerable increase in the use of chromoglycate (Intal) and salbutamol (Ventolin) while the use of the isoprenaline aerosols decreased (Wade and Hood, 1972b).

It has also been possible to study the geography of drug use. One of our first studies was of the use of insulin and oral hypoglycaemic drugs (Wade, Hadden, and Hood, 1972). The prescribing of insulin was remarkably evenly distributed throughout the province. But there were great variations in the prescribing of oral hypoglycaemic drugs (fig 3). At the time of the survey (1966) the drugs being mainly used were tolbutamide and chlorpropamide. A detailed survey was made of the use of these drugs in Londonderry and Newry, low- and high-use areas respectively (table VII). It was found that in each city almost exactly the same proportion of persons were receiving oral hypoglycaemic drugs. The difference in overall use was due to the low daily doses prescribed for each patient in Londonderry and the high doses in Newry. I suspect that the main reason for this difference was that in Londonderry the diabetic clinic had a dietician who gave advice and detailed supervision of patients. In Newry there was no dietician. These observations may be important in relation to the anxiety raised by the University Diabetic Group Project (1970) in the USA. The incidence of cardiovascular complications found in that survey was higher in patients on the oral antidiabetic drugs than in those on insulin. This might be investigated in areas where the use of the oral drugs differs greatly.

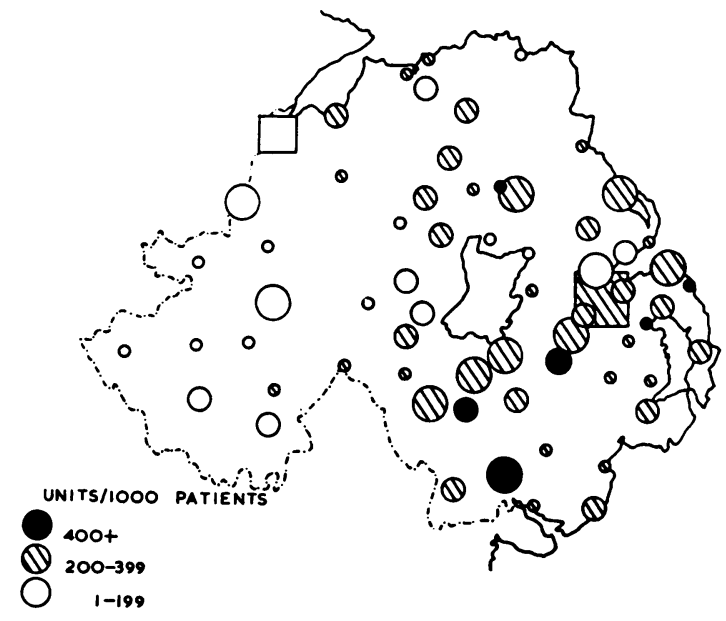

Fig 3 The prescribing of oral hypoglycaemic drugs in Northern Ireland 1966.

The circles indicate the population in different towns and rural areas. The prescribing density is represented by the shading and hatching.

\begin{tabular}{lcc}
\hline & Newry & Derry \\
\hline Diabetic patients & 39 & 101 \\
$\begin{array}{l}\text { Diabetics per } 1000 \text { patients } \\
\text { Units of antidiabetic drugs/1000 }\end{array}$ & $1 \cdot 21$ & $1 \cdot 33$ \\
$\begin{array}{l}\text { patients/month } \\
\text { Units of antidiabetic drugs/month/per } \\
\text { doctor }\end{array}$ & 411 & 132 \\
\hline
\end{tabular}

Table VII Prescribing of oral antidiabetic drugs in two towns 


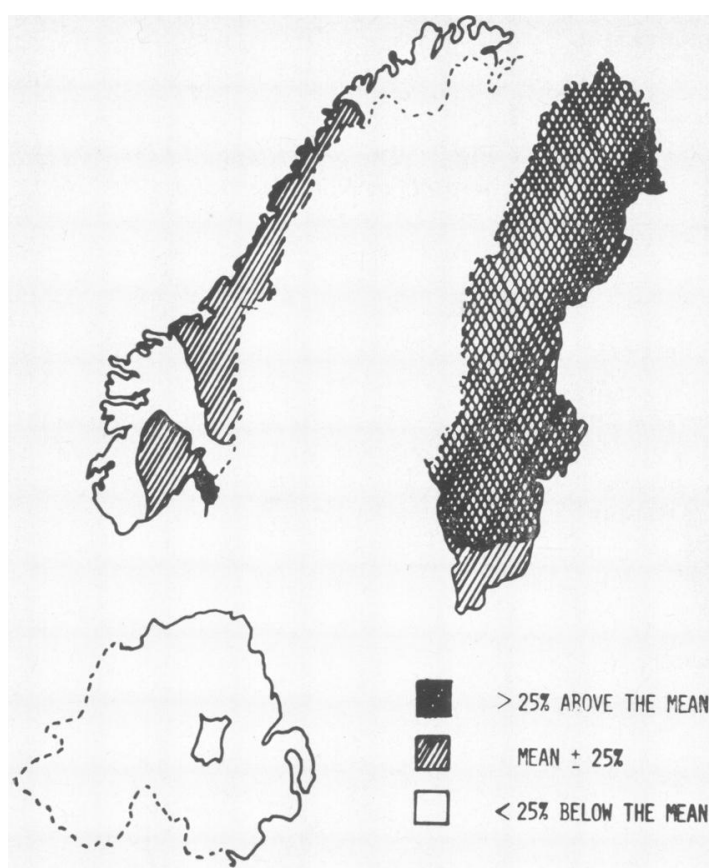

Fig 4 The prescribing of oral hypoglycaemic drugs in Norway (top left), Sweden (top right) and Northern Ireland (bottom left) in 1972.

Recently it has been possible to carry out a study of the prescribing of the oral hypoglycaemic drugs in Northern Ireland, Norway, and Sweden (Crooks, Elmes, Friebel, Halse et al, 1974). The analysis is not yet complete but it is clear that the differences in prescribing found within Northern Ireland are very much smaller than the differences which exist between these three countries (fig 4). It seems to me that if large differences in the prescribing of drugs are occurring it may be possible not only to learn more about the incidence of adverse reactions to the drug but also to assess what value its use is, by comparing the morbidity, span of life, and mortality of communities in which the drug is used with those where it is not used. It has been particularly interesting to find that in one area of Sweden, the county of Jamtland, it is possible not only to

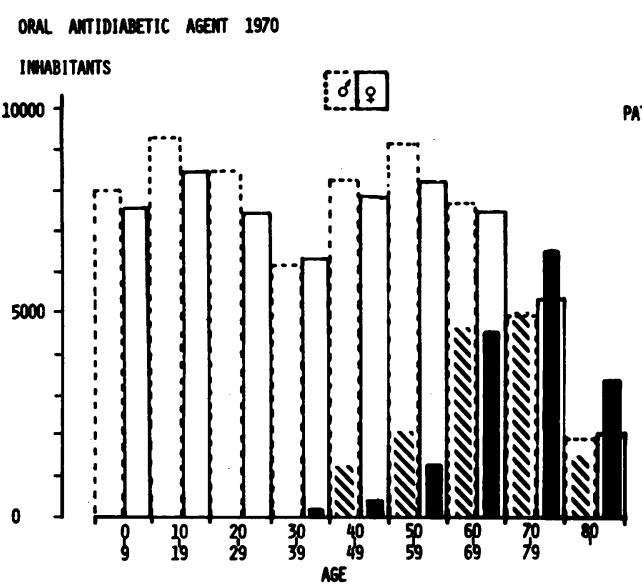

Fig 5 Prescribing of oral antidiabetic drugs in Jamtland, 1970.

The age and sex of the community is shown in open histograms and superimposed is the hatched and shaded histogram of patients receiving oral antidiabetic drugs.

enumerate all the citizens by age and sex but also to identify who in the community gets a particulas drug. Cardiac glycosides, antihypertensive drugs:

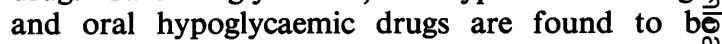
prescribed predominantly to the over 60 s (fig 5 ).

It is likely that studies in other countries woul $\$$ show other important differences in the use of drugs Some eight years ago a study of the sales of ant $\mathrm{B}$ biotics in six European countries showed that at that time a quarter of all antibiotics used in German was chloramphenicol (table VIII) (Engels and Siderius, 1968).

\section{Death and Drugs}

It has always seemed to me that the most important adverse reactions of drugs are those which cause of contribute to death. With Dr Tesh and with the cooperation of Professor Curran and his colleagues; I have recently arranged an investigation of the part that drugs may have played in the death of 100 patients coming to necropsy at the Quee

\begin{tabular}{|c|c|c|c|c|c|c|}
\hline & France & $U K$ & West Germany & Belgium & Sweden & Holland \\
\hline Penicillins & 20 & 35 & 45 & 11 & 55 & 30 \\
\hline Ampicillins & 1 & 15 & 5 & 13 & 15 & 30 \\
\hline Tetracyclines & 40 & 35 & 20 & 20 & 25 & 30 \\
\hline Macrolides & 8 & 5 & 1 & 30 & 2 & 2 \\
\hline Combined tetracyclines and macrolides & 8 & 2 & 1 & 15 & $\mathbf{0}$ & 1 \\
\hline Chloramphenicol & 5 & 1 & 25 & 1 & 1 & 1 \\
\hline Others & 18 & 7 & 3 & 10 & 2 & 6 \\
\hline
\end{tabular}

Table VIII Sales of antibiotics in Europe. As percentage of total sales within each country 


\begin{tabular}{lc}
\hline Important Factors Contributing to Death & No. of Patients \\
\hline After operation & 12 \\
Diagnostic procedures & 4 \\
Drugs & 20 \\
Cessation of therapy & 4 \\
Bed rest & 3 \\
None of above & 57 \\
\hline
\end{tabular}

Table IX Analysis of 100 necropsies

Elizabeth Hospital, Birmingham (table IX). Although the assessment is rather subjective and the analysis incomplete, it would appear that the use of drugs, or the cessation of drug therapy, has played a part in the death of at least a quarter of the patients. To me this suggests that a comprehensive multicentre survey carried out by pathologists might be of considerable value. It might lead to a more cautious use of drugs by physicians and it might identify drug hazards which are not yet recognized.

\section{References}

Crooks, J., Elmes, P. C., Friebel, H., Halse, M., Halvorsen, T., Hood, H., Lunde, P. K., Moe, M., Sjoquist, F., Wade, O. L., and Westerholm, B. (1975). Preliminary findings of WHO working party. (In press.)

Custer, R. P. (1946) Aplastic anaemia in soldiers treated with atebrine (quinacrine). Amer. J. med Sci. 212, 211.

Engels, A., and Siderius, P. (1968). The consumption of drugs. Report of a study, 1966-67. Unpublished WHO Working Document, EURO 1301, Copenhagen.

Erslev, A. J., and Wintrobe, M. M. (1962). Detection and prevention of drug induced blood dyscrasias. J. Amer. med. Ass., 181, 114-119.
Hurwitz, N., and Wade, O.'L. (1969). Intensive hospital monitoring of adverse reactions to drugs. Brit. med J., 1, 531.

Inman, W. H. W., and Adelstein, A. M. (1969). Rise and fall of asthma mortality in England and Wales in relation to use of pressurised aerosols. Lancet, 2, 279-285.

Inman, W. H. W., and Vessey, M. P. (1968). Investigation of deaths from pulmonary, coronary and cerebral thrombosis and embolism in women of child bearing age. Brit. med. J., 2, 193-199.

Lawrie, E., Brunton, T. L., Bomford, G., and Hakim, R. D. (1890). Report of the Second Hyderabad Chloroform Commission. Lancet, 1, 149-159.

McDonald, S. (1918). Acute yellow atrophy in syphilis. Brit. med. J., 1, 76-78.

McKendrick, J. G., Coats, J., and Newman, D. (1880). Report on the action of anaesthetics. Brit. med. J., 2, 957-972.

Medical Research Council (1922). Toxic effects following the employment of arsenobenzenol preparations. Spec. Rep. Ser. med. Res. Coun. (Lond.), 66.

Medical Research Council (1963). Assessment of drug toxicity. Internal paper, $63 / 658$.

Meyler, L. (1957). Side Effects of Drugs. Excerpta Medica Foundation, Amsterdam.

Meyler, L., and Herxheimer, A. (1968). Side Effects of Drugs, Vol. VI. Excerpta Medica Foundation, Amsterdam.

Taussig, H. B. A. (1962). A Study of the German outbreak of phocomelia. J. Amer. med. Ass., 180, 1106-1114.

University Diabetic Group Project (1970). A study of the effects of hypoglycaemic agents on vascular complications in patients with adult onset diabetes. Diabetes, 19, 747-830.

Wade, O. L. (1968). The computer and drug prescribing. In Computers in the Service of Medicine, edited by G. McLachlan and R. A. Shegog, vol. 1, pp.153-161. Oxford University Press, London.

Wade, O. L. (1970). Pattern of drug-induced disease in the community: an unsolved enigma. Brit. med. Bull., 26, 240-244.

Wade, O. L., Hadden, D. R., and Hood, H. (1973). The prescribing of drugs used in the treatment of diabetes. Brit. J. prev. soc. Med., 27, 44-48.

Wade, O. L., and Hood, H. (1972a). An analysis of prescribing of an hypnotic in the community. Brit. J. prev. soc. Med., 26, 121-128.

Wade, O. L., and Hood, H. (1972b). Prescribing of drugs reported to cause adverse reactions. Brit. J. prev. soc. Med., 26, 205-211 